\title{
Extending computational models of astrocyte- neuron interactions with biochemical mechanisms on the postsynaptic terminal
}

\author{
Aušra Saudargienè ${ }^{1}$, Tiina Manninen ${ }^{2}$, Riikka Havela², Marja-Leena Linne $2^{2^{*}}$ \\ From 24th Annual Computational Neuroscience Meeting: CNS*2015 \\ Prague, Czech Republic. 18-23 July 2015
}

There is increasing evidence that astrocytes not only interact with each other but also with adjacent neurons in the neural circuitry in a variety of brain areas. Many biophysical and biochemical mechanisms have been proposed to explain these interactions in vitro. Based on the experimental literature, the mechanisms involved seem to depend not only on the developmental stage of an animal but also on the brain area, neural circuitry, as well as on the experimental technique used to characterize the phenomena. Using biophysically and biochemically detailed compartmental models, we are interested in understanding how these interactions between neurons and astrocytes may regulate information processing and, notably, different forms of synaptic plasticity [1]. In this study, we designed a new model of the so-called tripartite synapse. The tripartite synapse is a concept of synaptic physiology in which there are three parts of a synapse: the presynaptic and postsynaptic terminals, and an astrocyte in between them [2]. Many previous studies in vitro have shown that gliotransmitters like glutamate are released from astrocytes into the synaptic cleft following activation of presynaptic or postsynaptic terminals, or activation of the astrocyte itself [3]. However, none of the previous modeling studies incorporate all features necessary to understand the complex interactions in full detail. We extend beyond these previously published fundamental, yet relatively simplistic representations (see, e.g., [4]). We describe the postsynaptic terminal using a two-compartmental approach, in addition to the presynaptic terminal and the astrocyte. We specifically address the postsynaptic mechanisms and their role in activating

\footnotetext{
* Correspondence: marja-leena.linne@tut.fi

${ }^{2}$ Department of Signal Processing, Tampere University of Technology,

Tampere, Finland

Full list of author information is available at the end of the article
}

astrocytic calcium signaling and subsequent gliotransmission. By introducing realistic model components on the postsynaptic terminal, such as voltage-dependent receptor channels and the G-protein activated signaling cascades, we observe stimulus-dependent changes in astrocyte calcium oscillations leading to activation of not only astrocytes, but also of adjacent neurons. The longterm goal of our work is to develop detailed models of astrocyte-neuron interactions for different brain areas which allow testing experimentally evoked hypothesis, as well as some controversies in the field (see, e.g., [5]). These models will open up new avenues to assess the effects of numerous mechanisms of astrocytes on the dynamics of local neuronal networks. Only through systematic integration of in vitro and in silico work will we be able to understand how astrocytes may contribute to brain information processing and plasticity.

\begin{abstract}
Acknowledgements
The research leading to these results has received funding from the European Union Seventh Framework Programme (FP7/2007-2013) under grant agreement $n^{\circ} 604102$ (HBP). This work was also supported by the Academy of Finland, application number 126556, as well as the Emil Aaltonen Foundation and Otto A. Malm Foundation for T.M. Tampere University of Technology Graduate School is acknowledged for supporting R.H.
\end{abstract}

\section{Authors' details}

'Department of Informatics, Vytautas Magnus University, Kaunas, Lithuania. ${ }^{2}$ Department of Signal Processing, Tampere University of Technology, Tampere, Finland.

Published: 18 December 2015

\section{References}

1. Paixão S., Klein R: Neuron-astrocyte communication and synaptic plasticity. Curr Opin Neurobiol 2010, 20:466-473.

2. Araque A, Parpura V, Sanzgiri RP, Haydon PG: Tripartite synapses: glia, the unacknowledged partner. Trends Neurosci 1999, 22(5):208-215. 
3. Parpura V, Haydon P: Physiological astrocytic calcium levels stimulate glutamate release to modulate adjacent neurons. Proc Natl Acad Sci USA 2000, 97:8629-8634.

4. Volman V, Ben-Jakob E, Levine $H$ : The astrocyte as gatekeeper of synaptic information transfer. Neural Comput 2007, 19:303-326.

5. Volterra A, Liaudet N, Savtchouk I: Astrocyte $\mathrm{Ca}^{2+}$ signalling: an unexpected complexity. Nature Rev Neurosci 2014, 15:327-335.

doi:10.1186/1471-2202-16-S1-P148

Cite this article as: Saudargiene et al.: Extending computational models of astrocyte-neuron interactions with biochemical mechanisms on the postsynaptic terminal. BMC Neuroscience 2015 16(Suppl 1):P148.

Submit your next manuscript to BioMed Central and take full advantage of:

- Convenient online submission

- Thorough peer review

- No space constraints or color figure charges

- Immediate publication on acceptance

- Inclusion in PubMed, CAS, Scopus and Google Scholar

- Research which is freely available for redistribution

Submit your manuscript at www.biomedcentral.com/submit
C Biomed Central 